\title{
"Ears of the Lynx" MRI Sign Is Associated with SPG11 and SPG15 Hereditary Spastic Paraplegia
}

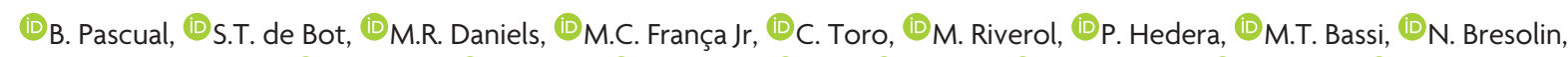

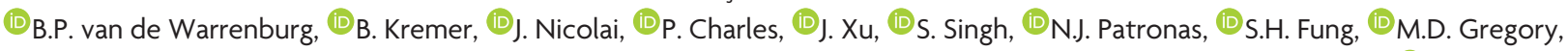 \\ and ${ }^{\circ}$ J.C. Masdeu
}

\begin{abstract}
BACKGROUND AND PURPOSE: The "ears of the lynx" MR imaging sign has been described in case reports of hereditary spastic paraplegia with a thin corpus callosum, mostly associated with mutations in the spatacsin vesicle trafficking associated gene, causing Spastic Paraplegia type 11 (SPG11). This sign corresponds to long $\mathrm{T} 1$ and $\mathrm{T} 2$ values in the forceps minor of the corpus callosum, which appears hyperintense on FLAIR and hypointense on T1-weighted images. Our purpose was to determine the sensitivity and specificity of the ears of the lynx MR imaging sign for genetic cases compared with common potential mimics.
\end{abstract}

MATERIALS AND METHODS: Four independent raters, blinded to the diagnosis, determined whether the ears of the lynx sign was present in each of a set of 204 single anonymized FLAIR and T1-weighted MR images from 34 patients with causal mutations associated with SPGII or Spastic Paraplegia type 15 (SPG15). 34 healthy controls, and 34 patients with multiple sclerosis.

RESULTS: The interrater reliability for FLAIR images was substantial (Cohen $\kappa, 0.66-0.77$ ). For these images, the sensitivity of the ears of the lynx sign across raters ranged from 78.8 to 97.0 and the specificity ranged from 90.9 to 100 . The accuracy of the sign, measured by area under the receiver operating characteristic curve, ranged from very good (87.1) to excellent (93.9).

CONCLUSIONS: The ears of the lynx sign on FLAIR MR imaging is highly specific for the most common genetic subtypes of hereditary spastic paraplegia with a thin corpus callosum. When this sign is present, there is a high likelihood of a genetic mutation, particularly associated with SPGIl or SPG15, even in the absence of a family history.

ABBREVIATIONS: AUC $=$ area under the curve; HSP-TCC $=$ hereditary spastic paraplegia with a thin corpus callosum; ROC $=$ receiver operating characteristic curve

A utosomal recessive hereditary spastic paraplegia with a thin corpus callosum (HSP-TCC for short) presents clinically as a progressive spastic paraplegia, usually beginning during infancy or puberty, and is often associated with cognitive impairment, occasionally antedating the onset of paraparesis. ${ }^{1-6}$ Both symptoms worsen slowly for decades. Mutations in the spatacsin vesicle

Received July 5, 2018; accepted after revision October 30.

From the Departments of Neurology (B.P., M.R.D., J.C.M.), Biostatistics (J.X.), and Radiology (S.S., S.H.F.), Houston Methodist Research Institute, Houston, Texas; Department of Neurology (S.T.d.B.), Leiden University Medical Centre, Leiden, the Netherlands; Department of Neurology (M.C.F.), University of Campinas, Campinas, Brazil; National Institutes of Health Intramural Research Program (C.T., N.J.P., M.D.G.), Bethesda, Maryland; Department of Neurology (M.R.), Clínica Universidad de Navarra, Pamplona, Spain; Department of Neurology (P.H.), Vanderbilt University Medical Center, Nashville, Tennessee; Laboratory of Molecular Biology (M.T.B.), Scientific Institute Istituto di Ricovero e Cura a Carattere Scientifico E. Medea, Bosisio Parini, Lecco, Italy; Department of Neuroscience and Mental Health (N.B.), University Hospital Policlinico Ca'Granda, University of Milan, Milan, Italy; Department of Neurology (B.P.v.d.W.), Donders Institute for Brain, Cognition, and Behaviour, Radboud University Medical Center, Nijmegen, the Netherlands; Department of Neurology (B.K.), University Medical Center Groningen, Groningen, the Netherlands; Department of Neurology (J.N.), Maastricht University Medical Centre, Maastricht, the Netherlands; and Department of Genetics (P.C.), Hôpital Pitié-Salpêtrière, Paris, France. trafficking associated (SPG11) gene, coding for spatacsin, are most commonly identified in these patients. ${ }^{1-6}$ Mutations in the gene encoding spastizin (zinc finger fyve domain-containing protein 26 , ZFYVE26, causing SPG15) or other genes are rarer. ${ }^{2,4,5,7}$ The disorder is transmitted as an autosomal recessive trait; thus, it is common for patients to present without a family history of the disease. ${ }^{4,6}$ Given the clinical presentation, these patients are most often studied with MR imaging to detect disorders affecting the brain and, particularly, the pyramidal tract. ${ }^{8} \mathrm{MR}$ imaging shows a thin corpus callosum, but this sign is not unique to HSP-TCC, ${ }^{9-17}$

This study was partially funded by the Chao, Graham, Harrison, and Nantz Funds of the Houston Methodist Foundation. Portions of the data studied were obtained under protocol OHSRP 12231 and were supported (in part) by the National Institutes of Mental Health Intramural Research Program.

This work does not necessarily reflect the views of the US government or the $\mathrm{Na-}$ tional Institutes of Health.

Please address correspondence to Belen Pascual, PhD, Nantz National Alzheimer Center, Stanley H. Appel Department of Neurology, 6560 Fannin St., Scurlock Tower, 8th Floor, Houston, TX 77030, email: bpascual@houstonmethodist.org 三 Indicates article with supplemental on-line table.

http://dx.doi.org/10.3174/ajnr.A5935 


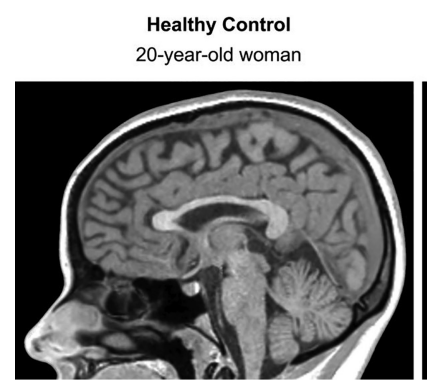

Patient with SPG11 mutation

15-year-old woman

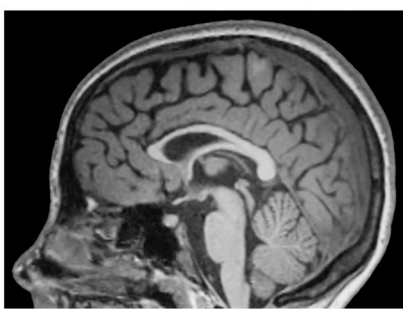

FIG 1. Corpus callosum size similar to normal in a patient with HSPTCC. The patient had mild cognitive impairment and a mild spastic paraparesis. She had SPG 11 pathogenetic mutations. The ear of the lynx sign in this patient is shown in Fig 2.
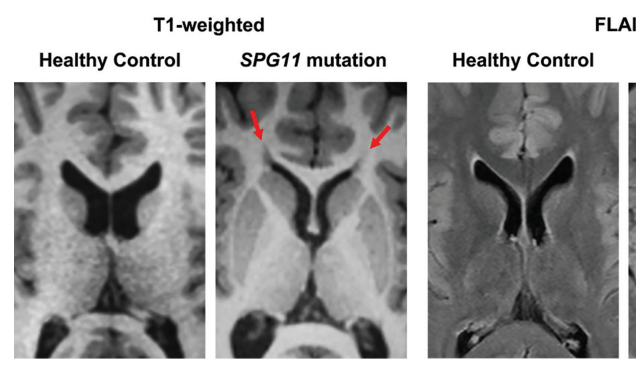

FLAIR

SPG11 mutation

FIG 2. Ears of the lynx on MR imaging. Axial images across the anterior forceps of the corpus callosum. Note an abnormality in the region of the forceps minor of the corpus callosum, corresponding to the genu fibers, which appear dark on T1-weighted and bright on FLAIR images (arrows). Midline sagittal images from the same individuals are seen in Fig 1.

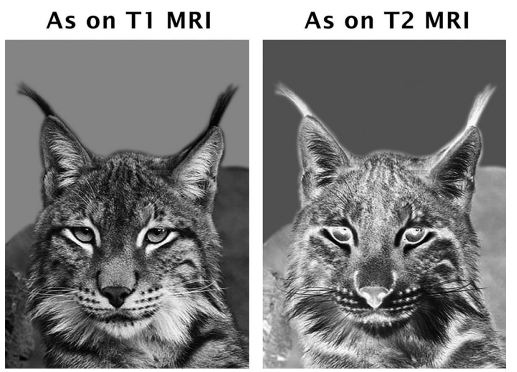

FIG 3. Ears of the lynx. Shown are the gray-scale and corresponding negative images of the head of a lynx. The hair tufts at the tip of the ears resemble the MR imaging finding described here. Modified with permission from an original photo taken by Aleksandar Vasic.

and there are patients with HSP-TCC caused by SPG11 mutations in whom the corpus callosum has an apparently normal thickness (Fig 1).

Another MR imaging feature may be helpful to lead to the diagnosis. A characteristic abnormality affecting the region of the forceps minor of the corpus callosum ${ }^{18,19}$ has been described as the "ears of the lynx" sign. ${ }^{20}$ The forceps minor of the corpus callosum, corresponding to the genu fibers, has prolonged T1 and T2 values. As a result, this region appears bright on T2-weighted and dark on T1-weighted images (Fig 2). On axial sections, the abnormality bears a remarkable resemblance to the ears of a lynx, with the areas of abnormal signal reminiscent of the tufts of hair crowning the tips of the ears of this animal (Fig 3).

If specific, the presence of this MR imaging finding in a seemingly sporadic case could be very useful to guide genetic testing or
Table 1: Demographics

\begin{tabular}{lccc}
\hline & \multicolumn{3}{c}{ Diagnosis } \\
\cline { 2 - 4 } & SPG11 $(\boldsymbol{n}=31)$ & & \\
& or SPG15 $(\boldsymbol{n}=\mathbf{3})$ & & Healthy \\
& Mutations & MS & Control \\
\hline Number & 34 & 34 & 34 \\
Sex, female/male & $16: 18$ & $16: 18$ & $16: 18$ \\
Mean age (SD) at MRI (yr) & $24.6(7.8)$ & $25.0(6.8)$ & $24.6(7.5)$ \\
\hline
\end{tabular}

help in interpreting genetic findings. Thus, separating patients with genetic mutations from those who may show a similar radiologic finding caused by more common etiologies, such as gliosis at the calloso-caudate angle of the frontal horn of the lateral ventricles $^{21}$ or multiple sclerosis, is much more relevant in terms of imaging than helping to differentiate among rare genetic variants. If a genetic disorder is suggested by the radiologic picture, a detailed genetic study should be performed to determine the exact genetic etiology. Therefore, our objective was to determine the sensitivity and specificity of this sign for patients with known genetic mutations associated with HSP-TCC versus potentially similar common patterns in this age group, such as gliosis at the calloso-caudate angle or demyelinating disease. Thus, we compared the MRIs of patients with HSP-TCC who were found by genetic testing to have causal mutations associated with SPG11 or SPG15 with those of healthy controls and of patients with multiple sclerosis, a common cause of white matter changes in an age group similar to the HSP-TCC sample.

\section{MATERIALS AND METHODS}

All procedures were approved by the Human Studies Committees of the institutions involved, including the National Institutes of Health Office of Human Subjects Research for the healthy controls and patients with MS. In all cases, only retrospective, anonymized information was used for the study; therefore, individual written informed consent was waived. Patients with HSP-TCC had been recruited between 2002 and 2014 at 9 institutions, listed in the authors' affiliations. Nine of these patients had been included in a study ${ }^{22}$ reporting on the clinical course of genetic variants of HSP-TCC, not on the radiologic sign described in this article. Another 5 patients had been included in a study ${ }^{23}$ reporting diffusion tensor imaging changes in white matter and brain volume in HSP-TCC, but this study did not discuss the radiologic sign studied here. Finally, another 4 patients with HSP-TCC had been included in the original report of the ears of the lynx sign, ${ }^{20}$ but its sensitivity or specificity was neither studied nor described in that article. Patients with MS and healthy controls had participated in other studies at the National Institutes of Health, but we had access to only their anonymized MRIs, obtained from 2002 to 2013, which were selected to match the HSPTCC sample in age and sex. All patients with HSP-TCC had identified pathogenic mutations, 31 associated with SPG11 and 3 with SPG15. Each of the 3 groups (HSP-TCC, MS, healthy controls) consisted of 34 subjects, split almost evenly across sexes, with a mean age at MR imaging of approximately 25 years (Table 1 ).

Anonymized MRIs were used for all groups. One axial T2 FLAIR and one T1-weighted image across the anterior forceps of the corpus callosum (Fig 2) of each patient with HSP-TCC and each control (healthy or MS) were randomized for presentation to 
the evaluating raters. Thus, each rater read 204 images blindly. Single images were presented on a computer screen containing the image to be evaluated and buttons to indicate the presence or absence of the ears of the lynx sign and the quality of the image. Raters included 3 US board-certified radiologists with Certificate of Additional Qualification in Neuroradiology, with an average experience of 22 years of practice (range, 11-32 years), and a board-certified neurologist with 12 years of experience in imaging. Before reading the images blindly, the raters were trained to recognize the ears of the lynx with 4 images positive for it and 4 images negative for it, including both T2 and T1 studies. They were not given information on the diseases of the patients but were only shown the morphology of the ears of the lynx sign. For

Table 2: Interrater reliability (Cohen $\kappa)$

\begin{tabular}{lcc}
\hline & $\begin{array}{c}\text { Cohen } \boldsymbol{\kappa} \text { for } \\
\text { FLAIR }(95 \% \text { CI) }\end{array}$ & $\begin{array}{c}\text { Cohen } \boldsymbol{\kappa} \text { for } \\
\text { TI-Weighted }(95 \% \mathrm{CI})\end{array}$ \\
\hline Rater 1 vs 2 & $0.74(0.60-0.88)$ & $0.51(0.32-0.71)$ \\
Rater 2 vs 3 & $0.74(0.60-0.88)$ & $0.42(0.24-0.63)$ \\
Rater 3 vs 4 & $0.77(0.63-0.91)$ & $0.75(0.54-0.96)$ \\
Rater 1 vs 3 & $0.66(0.51-0.82)$ & $0.59(0.38-0.80)$ \\
Rater 2 vs 4 & $0.71(0.56-0.86)$ & $0.40(0.20-0.60)$ \\
Rater 1 vs 4 & $0.73(0.59-0.87)$ & $0.62(0.42-0.83)$ \\
All raters & $0.72(0.61-0.82)$ & $0.53(0.35-0.69)$ \\
\hline
\end{tabular}

Table 3: ROC results with sensitivity and specificity for FLAIR and T1-weighted images

\begin{tabular}{|c|c|c|c|}
\hline & \multicolumn{3}{|c|}{ ROC Results } \\
\hline & $\begin{array}{c}\text { AUC } \\
(95 \% \mathrm{Cl})\end{array}$ & $\begin{array}{l}\text { Sensitivity } \\
(95 \% \mathrm{Cl})\end{array}$ & $\begin{array}{l}\text { Specificity } \\
(95 \% \mathrm{CI})\end{array}$ \\
\hline \multicolumn{4}{|c|}{$\begin{array}{l}\text { Sensitivity and specificity for } \\
\text { FLAIR images }\end{array}$} \\
\hline Rater 1 & $93.9(89.4-98.5)$ & $97.0(84.2-99.9)$ & $90.9(81.3-96.6)$ \\
\hline Rater 2 & $87.1(79.7-94.5)$ & $81.8(64.5-93.0)$ & $92.4(83.2-97.5)$ \\
\hline Rater 3 & $87.1(79.6-94.6)$ & 78.8 (61.1-91.0) & $95.5(87.3-99.1)$ \\
\hline Rater 4 & $89.4(82.3-96.5)$ & $78.8(61.1-91.0)$ & $100(94.6-100)$ \\
\hline \multicolumn{4}{|c|}{$\begin{array}{c}\text { Sensitivity and specificity for } \\
\text { T1-weighted images }\end{array}$} \\
\hline Rater 1 & $84.8(76.1-93.5)$ & 71.4 (51.3-86.8) & $98.2(90.4-100)$ \\
\hline Rater 2 & $81.3(72.0-90.5)$ & 75.0 (55.1-89.3) & 87.5 (75.9-94.8) \\
\hline Rater 3 & $68.8(59.4-78.1)$ & $39.3(21.5-59.4)$ & $98.2(90.4-100)$ \\
\hline Rater 4 & $69.6(60.4-78.9)$ & $39.3(21.5-59.4)$ & $100(93.6-100)$ \\
\hline
\end{tabular}

the unknown images, the raters were asked to make a forced choice, deciding whether the image contained the ears of the lynx sign. In addition, they had to define whether each image was of good or poor quality.

\section{Statistical Analysis}

This is a retrospective case-control study. Given the absence of previous studies on the sensitivity and specificity of the ears of the lynx sign, we arrived at the sample size by following guidelines for studies with an unknown effect size. ${ }^{24}$ The Cohen $\kappa$ statistic was used to calculate interrater reliability. The degree of agreement was interpreted on the basis of the $\kappa$ coefficients as follows: $0-0.2$, poor; 0.21-0.4, fair; 0.41-0.6, moderate; 0.61-0.8, substantial; $0.81-1$, almost perfect. ${ }^{25}$ Sensitivity, specificity, and the $95 \%$ CIs for T1-weighted and FLAIR images were calculated. The area under the curve (AUC) was obtained from the logistic regression model. The logistic regression model with cluster, which allowed interrater correlation, was also used to calculate the effect of the rated quality of images on the agreement of the rating with the true allocation of each image. All analyses were performed with STATA version 15 (StataCorp, College Station, Texas). Statistical significance was defined as a 2 -tailed $P<.05$ for all tests.

\section{RESULTS}

The interrater reliability for FLAIR images was substantial, ranging from 0.66 to 0.77 . For T1-weighted images, it was moderate to substantial, ranging from 0.51 to 0.75 (Table 2). In the T2 FLAIR images, the ears of the lynx sign sensitivity across raters ranged from 78.8 to 97.0 and the specificity ranged from 90.9 to 100 (Table 3). On T1-weighted images, the sign was not detected as often, with a sensitivity ranging from 39.3 to 75 , but the specificity was still high (87.5-100) (Table 3). The receiver operating characteristic curves (ROCs) showed better
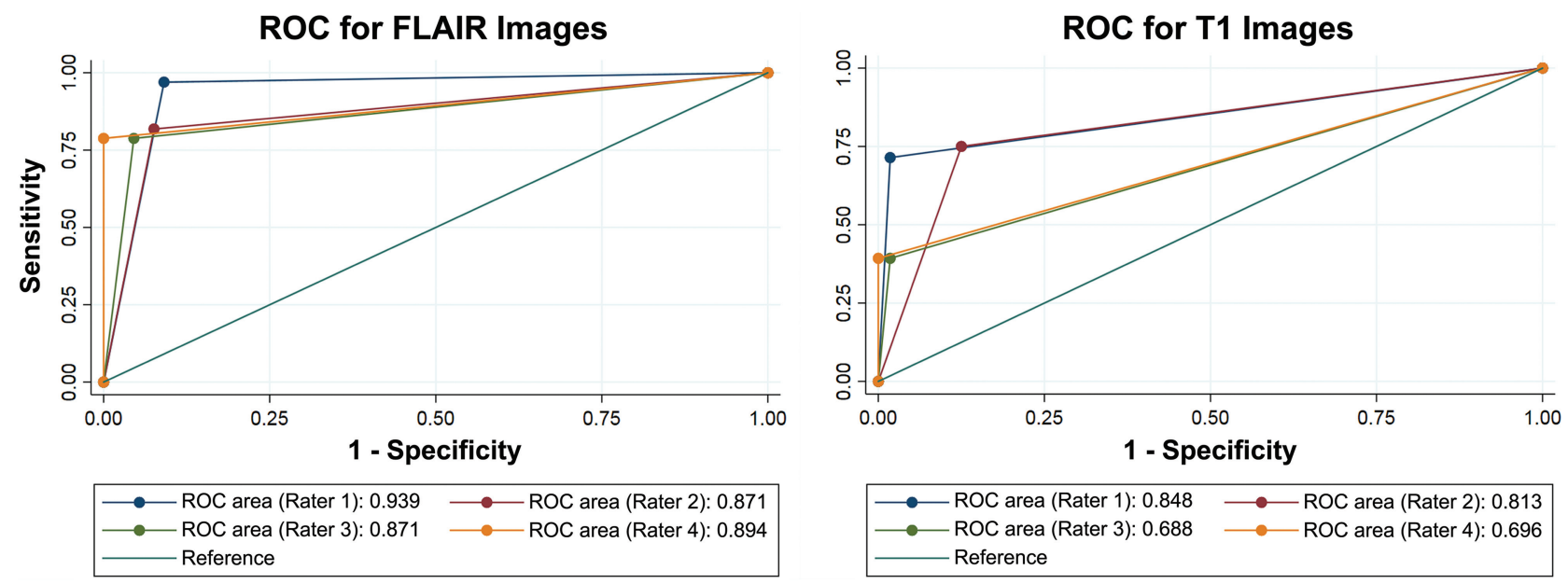

FIG 4. ROCs for TI-weighted and FLAIR images. The receiver operating characteristic curves show better discrimination for FLAIR than for T1-weighted images. For FLAIR images, the area under the ROC curve showed that the ears of the lynx sign performed in the very good-toexcellent range for a diagnostic test. 
discrimination for FLAIR than for T1-weighted images (Fig 4). For FLAIR images, the area under the ROC curve showed that the ears of the lynx sign performed in the very good-to-excellent (87.1-93.9) range for a diagnostic test. The quality of the images did not make a significant difference between the blinded rating and the true outcome $(P=.29)$ for FLAIR images, but it affected the agreement between the rating and outcome $(P<.001)$ for T1-weighted images (On-line Table).

\section{DISCUSSION}

Our study indicates that the ears of the lynx sign on axial FLAIR MR imaging is associated with HSP-TCC caused by genetic mutations characteristic of SPG11 and SPG15. We did not explore its association with other genetic mutations because this radiologic finding is probably not sufficient to make the genetic diagnosis; a genetic study is required. However, our study shows that the ears of the lynx sign is helpful to suggest a genetic disorder in a patient with an apparently sporadic spastic paraparesis or cognitive impairment. This is important because responsible mutations have been sought particularly in families with several affected members, ${ }^{3,6,26}$ though pathogenetic mutations often have sporadic presentations. ${ }^{4,6}$ As an imaging endophenotype, the ears of the lynx sign seems useful to suggest that genetic testing should be performed in patients who apparently have a sporadic rather than hereditary disorder or in patients with an atypical clinical picture. Our study determined that the ears of the lynx sign, particularly on axial FLAIR images, is highly associated with these mutations. In addition, when Whole Exome Sequencing finds genetic variants with potential pathogenicity that is nonetheless difficult to assess, the presence of the ears of the lynx sign on MR imaging would support the pathogenicity of the variants.

An important question is whether this MR imaging sign is present before the onset of clear-cut, defining clinical findings. Our study cannot answer this question. Only 1 patient was studied at age 11, when she had a low intelligence quotient but had not yet developed a spastic paraparesis, which started at 15 years of age. Already at 11 years of age, the ears of the lynx sign was present on her MR imaging. We hope that the description of the reliability of this sign may encourage its search at younger ages.

We studied mostly patients with mutations in the SPG11 gene, on chromosome 15 . Of the 34 patients with HSP-TCC, only 3 had mutations in another gene, causing SPG15; their MR imaging also contained the ears of the lynx sign. Therefore, this sign is not pathognomonic for SPG11 mutations but can probably be found with mutations that affect the corpus callosum in a manner similar to the SPG11 mutations. We are aware of a number of reports mentioning the ears of the lynx sign in patients with genetically determined HSP-TCC, ${ }^{7,22,27-31}$ but we are also aware of a single report of a somewhat similar finding in a patient with a possible Marchiafava-Bignami syndrome. ${ }^{32}$ However, in this case, the imaging finding was difficult to interpret in the published image; furthermore, that patient had a thin corpus callosum and no genetic testing. Given the range of phenotypic presentations of these genetic disorders, an atypical HSP-TCC could not be ruled out confidently in that case. The main potential mimic of the ears of the lynx sign is an area of gliosis observed in many healthy individuals at the calloso-caudate angle of the frontal horn of the lateral ventricles (Fig 2). ${ }^{21}$ However, this finding differs in morphology_it has a rounded capping, rather than flaming shapeand is smaller than the ears of the lynx. This normal finding, present in many of our MRIs with normal findings, probably led the raters to misclassify some cases, but this number was very small and null for some of the raters, as indicated in the Results section.

The raters were not asked to separate the series of images by diagnosis: They were completely unaware of the 3 diagnostic groups. They were only asked whether the ears of the lynx finding was present on an image. Therefore, other features of the image, such as other hyperintense lesions in multiple sclerosis scans, were supposed to be irrelevant to their readings.

Our study had a main limitation. It is difficult to rule out an effect of the presence of a thin corpus callosum on the decision of the raters. To minimize this issue, we did not reveal to the raters the disease entities to which the images corresponded. HSP-TCC is uncommon, and on postreading, only 2 of the raters indicated that they had some exposure to this disorder. One had read previously about 3 cases; the other, none. These 2 raters did not have better accuracy than the other 2. Because the images were presented in a sequence, we were able to evaluate the learning effects. Had the raters used a different feature in the image, namely the thin corpus callosum, to aid in accuracy, a learning effect would be expected. We did not detect better accuracy for images read later in the series.

\section{CONCLUSIONS}

The ears of the lynx MR imaging sign suggests the presence of a genetic mutation, likely characteristic of SPG11 or SPG15, in patients with cognitive impairment or a spastic paraparesis. In addition, the presence of this MR imaging finding in a subject identified as having a genotype associated with HSP-TCC suggests that the mutation is pathogenic.

\section{ACKNOWLEDGMENT}

Aleksandar Vasic obtained the original photo in Fig 3 and gave permission to use it.

Disclosures: Marcondes C. França Jr—UNRELATED: Fundação de Amparo à Pesquisa do Estado de São Paulo grant 2013/01766-7, Comments: The Fundação de Amparo à Pesquisa do Estado de São Paulo is a government agency in Brazil that funded genetic testing and MRI acquisitions.* Bart P. van de Warrenburg — UNRELATED: Grants/Grants Pending: Hersenstichting, ZonMw, Bioblast Pharma*; Royalties: Reed Elsevier*; Travel/Accommodations/Meeting Expenses Unrelated to Activities Listed: International Parkinson and Movement Disorders Society. Berry Kremer-UNRELATED: Board Membership: European Huntington's Disease Network/Child Health and Development Institute, Comments: travel cost reimbursements; Expert Testimony: Veduma Medical Expertise, Zaltbommel, the Netherlands; Comments: various book chapters; Stock/Stock Options: Fresenius, Germany. Joost Nicolai-UNRELATED: Payment for Lectures Including Service on Speakers Bureaus: SEPION, the Netherlands, Comments: Money was paid for organizing an epilepsy course twice a year for residents; Comments: Fee for several chapters in neurology books (Dutch). Joseph C. Masdeu—UNRELATED: Board Membership: GE Healthcare; Expert testimony: National Collegiate Athletic Association; Grants/ Grants Pending: Avanir Pharmaceuticals, Acadia, Biogen, Eli Lilly, AbbVie, Novartis, National Institutes of Health, Comments: clinical trials*; Payment for Lectures Including Service on Speakers Bureaus: Eli Lilly, Comments: amyloid imaging; Royalties: Walters Kluwer, Comments: localization in Neurology; Travel/Accommodations/Meeting Expenses Unrelated to Activities Listed: International Collaboration with Siemens. * Michael D. Gregory-UNRELATED: Employment: National Institutes of Mental Health, Inova Medical Group. *Money paid to the institution. 


\section{REFERENCES}

1. Chrestian N, Dupré N, Gan-Or Z, et al. Clinical and genetic study of hereditary spastic paraplegia in Canada. Neurol Genet 2017;3:e122 CrossRef Medline

2. Goizet C, Boukhris A, Maltete D, et al. SPG15 is the second most common cause of hereditary spastic paraplegia with thin corpus callosum. Neurology 2009;73:1111-19 CrossRef Medline

3. Hehr U, Bauer $P$, Winner B, et al. Long-term course and mutational spectrum of spatacsin-linked spastic paraplegia. Ann Neurol 2007; 62:656-65 CrossRef Medline

4. Kara E, Tucci A, Manzoni C, et al. Genetic and phenotypic characterization of complex hereditary spastic paraplegia. Brain 2016;139: 1904-18 CrossRef Medline

5. Pensato V, Castellotti B, Gellera C, et al. Overlapping phenotypes in complex spastic paraplegias SPG11, SPG15, SPG35 and SPG48. Brain 2014;137:1907-20 CrossRef Medline

6. Stevanin G, Azzedine H, Denora P, et al; SPATAX consortium. Mutations in SPG11 are frequent in autosomal recessive spastic paraplegia with thin corpus callosum, cognitive decline and lower motor neuron degeneration. Brain 2008;131:772-84 CrossRef Medline

7. Estrada-Cuzcano A, Martin S, Chamova T, et al. Loss-of-function mutations in the ATP13A2/PARK9 gene cause complicated hereditary spastic paraplegia (SPG78). Brain 2017;140:287-305 CrossRef Medline

8. Eichler F, Ratai E, Carroll JJ, et al. Inherited or acquired metabolic disorders. Handb Clin Neurol 2016;135:603-36 CrossRef Medline

9. Abdel-Hamid MS, Issa MY, Otaify GA, et al. PGAP3-related hyperphosphatasia with mental retardation syndrome: report of 10 new patients and a homozygous founder mutation. Clin Genet 2018;93: 84-91 CrossRef Medline

10. Barmherzig R, Bullivant G, Cordeiro D, et al. A new patient with intermediate severe Salla disease with hypomyelination: a literature review for Salla disease. Pediatr Neurol 2017;74:87-91.e82 CrossRef Medline

11. Depienne C, Nava C, Keren B, et al. Genetic and phenotypic dissection of 1q43q44 microdeletion syndrome and neurodevelopmental phenotypes associated with mutations in ZBTB18 and HNRNPU. Hum Genet 2017;136:463-79 CrossRef Medline

12. Flex E, Niceta M, Cecchetti S, et al. Biallelic mutations in TBCD, encoding the tubulin folding cofactor $\mathrm{D}$, perturb microtubule dynamics and cause early-onset encephalopathy. Am J Hum Genet 2016;99:962-73 CrossRef Medline

13. Kurata $\mathrm{H}$, Terashima $\mathrm{H}$, Nakashima $\mathrm{M}$, et al. Characterization of SPATA5-related encephalopathy in early childhood. Clin Genet 2016;90:437-44 CrossRef Medline

14. Lamers IJC, Reijnders MR, Venselaar $\mathrm{H}$, et al. Recurrent de novo mutations disturbing the GTP/GDP binding pocket of RAB11B cause intellectual disability and a distinctive brain phenotype. $A m J$ Hum Genet 2017;101:824-32 CrossRef Medline

15. Meng L, Donti T, Xia F, et al. Homozygous variants in pyrroline-5carboxylate reductase 2 (PYCR2) in patients with progressive microcephaly and hypomyelinating leukodystrophy. Am J Med Genet A 2017;173:460-70 CrossRef Medline

16. Rosti RO, Dikoglu E, Zaki MS, et al. Extending the mutation spectrum for Galloway-Mowat syndrome to include homozygous mis- sense mutations in the WDR73 gene. Am J Med Genet A 2016;170A: 992-98 CrossRef Medline

17. Sidhu M, Brady L, Tarnopolsky M, et al. Clinical manifestations associated with the N-Terminal-Acetyltransferase NAA10 gene mutation in a girl: Ogden syndrome. Pediatr Neurol 2017;76:82-85 CrossRef Medline

18. Kraus MF, Susmaras T, Caughlin BP, et al. White matter integrity and cognition in chronic traumatic brain injury: a diffusion tensor imaging study. Brain 2007;130:2508-19 CrossRef Medline

19. Mori S, Wakana S, van Zijl PC, et al. MRI Atlas of Human White Matter. Amsterdam: Elsevier; 2005, see: https://www.elsevier.com/ books/mri-atlas-of-human-white-matter/mori/978-0-444-51741-8

20. Riverol M, Samaranch L, Pascual B, et al. Forceps minor region signal abnormality "ears of the lynx": an early MRI finding in spastic paraparesis with thin corpus callosum and mutations in the spatacsin gene (SPG11) on chromosome 15. J Neuroimaging 2009;19:52-60 CrossRef Medline

21. Sze G, De Armond SJ, Brant-Zawadzki M, et al. Foci of MRI signal (pseudo lesions) anterior to the frontal horns: histologic correlations of a normal finding. AJR Am J Roentgenol 1986;147:331-37 CrossRef Medline

22. de Bot ST, Burggraaff RC, Herkert JC, et al. Rapidly deteriorating course in Dutch hereditary spastic paraplegia type 11 patients. Eur J Hum Genet 2013;21:1312-15 CrossRef Medline

23. França MC Jr, D’Abreu A, Maurer-Morelli CV, et al. Prospective neuroimaging study in hereditary spastic paraplegia with thin corpus callosum. Mov Disord 2007;22:1556-62 CrossRef Medline

24. Hertzog MA. Considerations in determining sample size for pilot studies. Res Nurs Health 2008;31:180-91 CrossRef Medline

25. Landis JR, Koch GG. The measurement of observer agreement for categorical data. Biometrics 1977;33:159-74 CrossRef Medline

26. Stevanin G, Santorelli FM, Azzedine H, et al. Mutations in SPG11, encoding spatacsin, are a major cause of spastic paraplegia with thin corpus callosum. Nat Genet 2007;39:366-72 CrossRef Medline

27. Faber I, Servelhere KR, Martinez ARM, et al. Clinical features and management of hereditary spastic paraplegia. Arq Neuropsiquiatr 2014;72:219-26 CrossRef Medline

28. Renvoisé B, Chang J, Singh R, et al. Lysosomal abnormalities in hereditary spastic paraplegia types SPG15 and SPG11. Ann Clin Transl Neurol 2014;1:379-89 CrossRef Medline

29. Giannoccaro MP, Liguori R, Arnoldi A, et al. Atypical late-onset hereditary spastic paraplegia with thin corpus callosum due to novel compound heterozygous mutations in the SPG11 gene. J Neurol 2014;261:1825-27 CrossRef Medline

30. Fraidakis MJ, Brunetti M, Blackstone C, et al. Novel compound heterozygous spatacsin mutations in a Greek kindred with hereditary spastic paraplegia SPG11 and dementia. Neurodegener Dis 2016; 16:373-81 CrossRef Medline

31. Chakrabarty S, Vijayakumar N, Radhakrishnan K, et al. Spastizin mutation in hereditary spastic paraplegia with thin corpus callosum. J Neurol 2016;263:2130-32 CrossRef Medline

32. Pacheco FT, Rego MM, do Rego JI, et al. "Ears of the lynx" sign in a Marchiafava-Bignami patient: structural basis and fiber-tracking DTI contribution to the understanding of this imaging abnormality. J Neuroimaging 2014;24:205-07 CrossRef Medline 